\title{
8
}
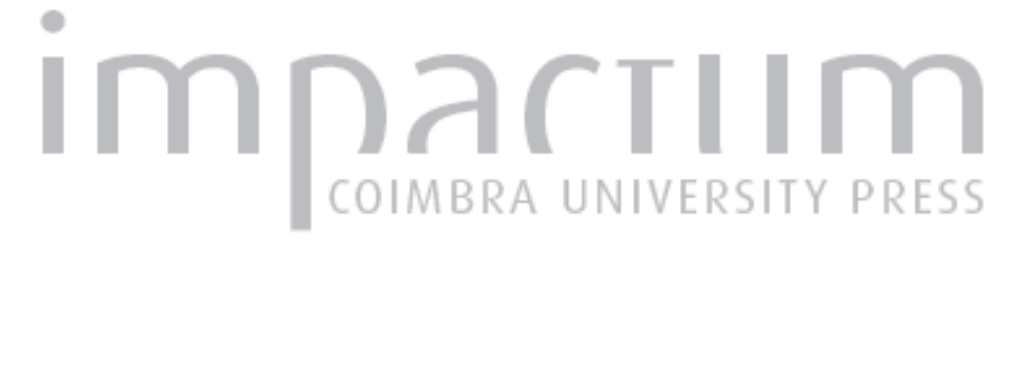

\section{Sócrates e as estátuas de Dédalo: algumas considerações sobre a Teché moral socrática}
Autor(es):
Dinucci, Aldo Lopes

Publicado por: Annablume Clássica; Imprensa da Universidade de Coimbra

URL persistente:

URI:http://hdl.handle.net/10316.2/24310

DOI:

DOI:http://dx.doi.org/10.14195/1984-249X_9_10

Accessed : $\quad$ 26-Apr-2023 10:54:30

A navegação consulta e descarregamento dos títulos inseridos nas Bibliotecas Digitais UC Digitalis, UC Pombalina e UC Impactum, pressupõem a aceitação plena e sem reservas dos Termos e Condições de Uso destas Bibliotecas Digitais, disponíveis em https://digitalis.uc.pt/pt-pt/termos.

Conforme exposto nos referidos Termos e Condições de Uso, o descarregamento de títulos de acesso restrito requer uma licença válida de autorização devendo o utilizador aceder ao(s) documento(s) a partir de um endereço de IP da instituição detentora da supramencionada licença.

Ao utilizador é apenas permitido o descarregamento para uso pessoal, pelo que o emprego do(s) título(s) descarregado(s) para outro fim, designadamente comercial, carece de autorização do respetivo autor ou editor da obra.

Na medida em que todas as obras da UC Digitalis se encontram protegidas pelo Código do Direito de Autor e Direitos Conexos e demais legislação aplicável, toda a cópia, parcial ou total, deste documento, nos casos em que é legalmente admitida, deverá conter ou fazer-se acompanhar por este aviso.

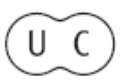




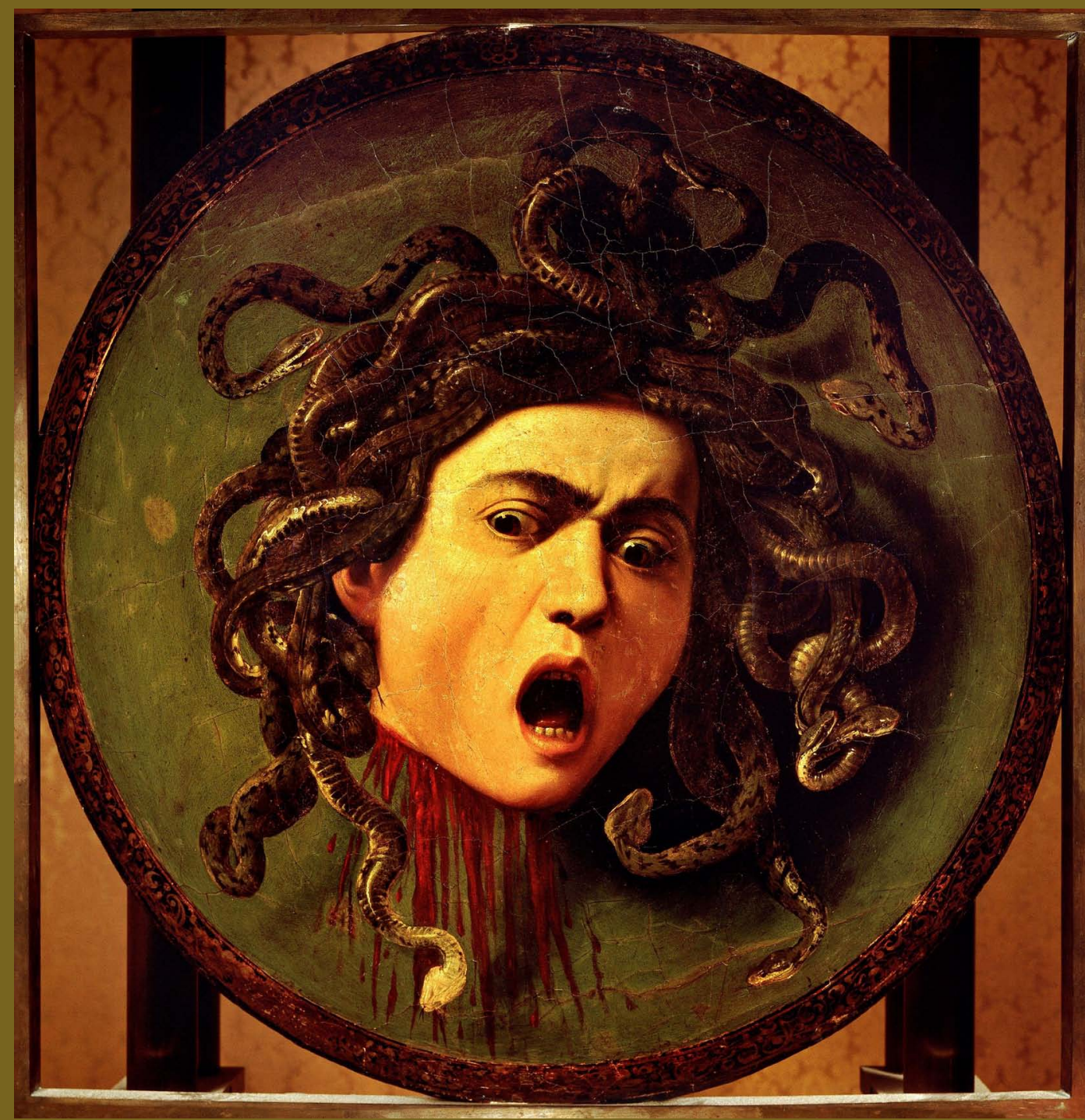

\section{R E V I S T A}
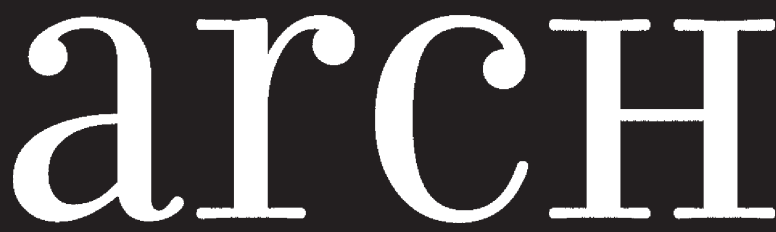
AS ORIGENS DO PENSAMENTO OCIDENTAL

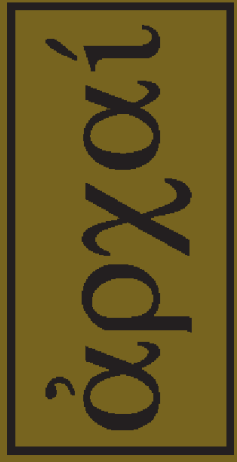

ARCHAI JOURNAL: ON THE ORIGINS OF WESTERN THOUGHT
arcHaI

arementam

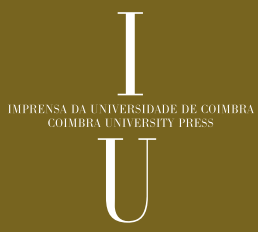

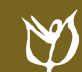

NNN 


\section{SÓCRATES E AS ESTÁTUAS DE DÉDAL0: ALGUMAS CONSIDERAÇÕES SOBRE A TECHNÉ MORAL SOCRÁTICA}

DINUCCI, A. L. (2012). “Sócrates e as estátuas de Dédalo: algumas considerações sobre a Techné moral e socrática". Archai n. 9 , jul-dez 2012, pp. 101-106.

RESUMO: Neste artigo, faremos uma análise da noção socrática de technê, que se desdobra em dois sentidos: uma sabedoria instável, humana e crítica (uma sophia de Dédalo), e uma sabedoria estável, divina e ideal. Ambas seguem o critério racional, o que implica uma concepção da alma segundo a qual as motivações são estritamente racionais.

PALAVRAS-CHAVES: Ética, Sócrates, Socratismo, Filosofia Clássica

ABSTRACT: In this paper we will make an analysis of the socratic notion of moral techne, which unfolds itself in two senses: an unstable, human and critic wisdom (a Daedalus' sophia), and an ideal, divine and stable wisdom. Both follow the rational criterion, implying a conception of the soul in which motivations are strictly rational.

Keywords: Ethics, Socrates, Socratism, Classical Philosophy
* Professor Associado da Universidade Federal de Sergipe.

1. Este Sócrates ao qual me refiro neste artigo é o personagem Sócrates dos Primeiros diálogos de Platão (Apologia, Carmides, Criton, Eutífron, Eutideno, Górgias, Hipias Menor, Íon, Lísias, Laques, Protágoras, Livro 1 da República e primeira parte do Mênon), diálogos que conteriam o pensamento do Sócrates histórico, que se coisas, por seu caráter aporético e exclusivamente ético e por não conter teorias propriamente platônicas, como a tese do Mundo das Ideias, a tese da imortalidade da alma e a teoria da reminiscência. caracterizaria, entre outras
Aldo Lopes Dinucci *

Há uma passagem no Eutífron que nos oferece uma clara evidência sobre certa característica do conhecimento moral buscado por Sócrates ${ }^{1}$ :

Eutífron: Mas, Sócrates, eu não sei como dizer o que eu quero dizer. Pois, seja qual for a afirmação que pronunciamos, de uma forma ou de outra ela se move e não fica onde nós a colocamos.

Sócrates: Tuas afirmações, Eutífron, são como as obras de meu ancestral Dédalo; e, se fosse eu aquele que as faz ou afirma, tu deverias rir de mim e dizer que, devido à minha relação com ele, minhas obras em palavras fogem e não ficam onde são colocadas. Mas agora, bem, as afirmações são tuas; é preciso, pois, alguma outra pilhéria; pois elas não ficam paradas, como tu mesmo vês.

Eutífron: Eu penso que a pilhéria cabe muito bem como está; pois eu não sou aquele que faz essas afirmações se moverem e não ficarem no mesmo lugar, mas tu és Dédalo; pois, no que me concerne, elas deveriam ter ficado [onde foram colocadas].

Sócrates: Aparentemente então, meu amigo, sou um artista mais inteligente que Dédalo, na medida em que ele fez apenas suas próprias obras se moverem, enquanto eu, como parece, dou movimento tanto às obras dos outros quanto às minhas. E a coisa mais estranha sobre minha arte é que eu sou inteligente contra 
minha vontade; pois eu preferiria que minhas palavras

fossem fixas e estáveis ao invés de possuir a sabedoria de Dédalo [...] (11b-e)

Vemos nessa passagem que Sócrates busca um conhecimento firme e estável, embora reconheça possuir apenas uma 'sabedoria de Dédalo', conseguindo tão somente demover as afirmações que são postas diante de si por seus interlocutores. Tal deslocamento das asserções alheias faz parte da missão socrática, que tem como objetivo imediato livrar os homens (a começar pelos interlocutores de Sócrates) de suas crenças inconsistentes que eles primeiramente veem como constituindo verdadeiro conhecimento moral.

A passagem apresentada acima nos é importante por evidenciar certa característica da technê moral socrática. Para Sócrates, o verdadeiro conhecimento moral, ou a sabedoria, deve ser estável e imutável e, portanto, eterno. Assim, embora sem evidenciar uma ontologia, Sócrates supõe uma, na medida em que busca determinar o eidos (essência) de certos conceitos morais. Uma vez atingido, tal conhecimento do eidos da virtude deveria necessariamente manter-se estável e imutável, ou não seria o que se busca. Com efeito, o objeto a ser definido é necessariamente estranho ao movimento e à mudança, alheio ao fluxo ininterrupto das coisas sensiveis, visto ser invariável e determinado.

Quanto a isso, nos é importante considerar o diálogo pseudo-platônico Minos. 0 que imediatamente nos chama a atenção nesse diálogo é que o autor fala sobre alguns pontos fundamentais relativos à noção socrática de technê moral.

0 diálogo começa com uma questão proposta por Sócrates: “0 que é a lei?” (313 a). Ao ser indagado a que lei se refere, o Sócrates responde, com indignação, que se refere à lei ("Há alguma diferença entre lei e lei, no que se refere ao caso particular de ser lei?", diz ele). Seu interlocutor responde dizendo-lhe que a lei consiste nas coisas aceitas pelo costume (ta nomizomena). Sócrates argumenta que tal não pode ser, pois, se assim o fosse, a linguagem consistiria nas coisas que são faladas, e a vista, nas coisas vistas (313 b-c). 0 interlocutor termina por dizer que a lei consiste em "nossas resoluções e decretos" e o Sócrates declara ser isso a opinião do Estado (314 b), chegando à conclusão de que a justiça "preserva a cidade e todas as outras coisas, enquanto a injustiça as destrói", e observando que, se a lei é uma resolução (to dogma) da cidade, e se, entre as resoluções, umas são boas e outras são más, então a lei não pode ser uma resolução, pois a lei nunca pode ser má (314 e). Sócrates, a seguir, declara que a lei é a opinião boa e verdadeira, e que a opinião verdadeira (alethes doxa) é a descoberta da realidade e que, portanto, a lei é descoberta da realidade (314 e - 315 a).

0 importante para o nosso ponto vem a seguir: o interlocutor observa que a lei não pode ser tal opinião verdadeira, pois as leis mudam com o tempo, e a realidade, tomada como algo invariável, não (315 a). E Sócrates insiste que a lei é a descoberta da realidade (315 a-b). 0 interlocutor passa então a citar vários exemplos que confirmam o fato de que as leis são distintas em diferentes Estados e povos e, mesmo num mesmo Estado, as leis mudam com o tempo (315 b-d). Sócrates inicia então uma argumentação que podemos assim resumir: os tratados de medicina abordam as realidades da medicina, contendo, portanto, as leis da medicina; e o mesmo vale para a agricultura, para a jardinagem, para a culinária, e as demais artes (316 d - 317 a). Sócrates acrescenta que tais artes precisam ser válidas para todo e qualquer homem, cidade e povo, devendo ser, dessa forma, objetivas. Assim, do mesmo modo, as leis sobre o governo do Estado (que compõem a arte de governar) devem ser válidas para todo e qualquer homem, cidade ou povo, necessitando, assim, ser também objetivas e universais. Por serem objetivas e universais, serão verdadeiras; sendo verdadeiras, serão boas, justas e inalteráveis.

Esses argumentos ilustram muito bem o anseio socrático por um conhecimento estável das coisas boas e más e, logo, da justiça. Tal busca é criticada por Aristóteles, tanto em razão dos problemas levantados pelo estagirita quanto às noções de ser e de bem, quanto pelo status que tal conhecimento possuiria, pois, para Aristóteles, a virtude não pode ser de modo algum nem uma technê nem uma epistemê:

Para a posse das virtudes - diz-nos o estagiritao conhecimento é de pouca ou nenhuma utilidade [...] 
visto que a virtude surge do desempenho repetido de ações justas e temperantes [...] É, por essa razão, correto que um homem se torna justo por realizar ações justas, e temperante por realizar ações temperantes; $e$ ninguém tem a mais remota chance de se tornar bom sem realizá-las. Mas a maioria dos homens, ao invés de realizar atos virtuosos, tem o recurso de discutir a virtude, e imaginam que estão filosofando e que isso os tornará homens bons. Fazendo tal, eles agem como inválidos que ouvem com atenção o que dizem os médicos, mas negligenciam inteiramente o cumprimento de suas prescrições. Esse tipo de filosofia não irá levá-los a um estado saudável da alma mais do que irá tal modo de tratamento produzir saúde no corpo. (ARISTÓTELES, 1994, 1105 b)

$\mathrm{Na}$ passagem acima vemos Aristóteles valorizar os elementos não-cognitivos da virtude, elementos cuja existência não é admitida por Sócrates, para quem a virtude é tão somente conhecimento sobre o bem e o mal. Para este último, tal conhecimento, uma vez alcançado, determinaria a moralidade do agente, tornando-o invariavelmente bom e justo. Essa concepção se explica pela própria noção de technê moral socrática, a qual, devido à sua inserção no eudaimonismo socrático, é vista como um conhecimento que produz uma disposição na alma que a torna necessariamente virtuosa. 0 conhecimento próprio da technê moral é, para Sócrates, condição necessária e suficiente para a felicidade. Dessa forma, o conhecimento estável da essência da virtude bastará para se atingir a eudaimonia (felicidade). Vemos assim que, dentro do âmbito do pensamento socrático, qualquer outra consideração que não a racional é absolutamente irrelevante no que se refere à busca pela felicidade e pela virtude. A posse da virtude, para Sócrates, não supõe qualquer componente não-cognitivo, e é justamente isso que explica sua afirmação de que ninguém comete um erro por sua própria vontade, ou melhor, a afirmação da impossibilidade da akrasia:

De acordo com Aristóteles o desejo de Sócrates de tratar as virtudes como se elas fossem artes produtivas reflete seu fracasso em reconhecer a importância de elementos não-cognitivos na virtude. Ao identificar a virtude com o conhecimento, Sócrates se livra das partes não-racionais da alma e, por essa razão, dos sentimentos e estados de caráter. É por isso que ele rejeita a possibilidade da incontinência [...] Se Sócrates não crê que há desejos não-racionais, então ele não pode reconhecer o desejo não-racional como uma fonte de erro que impede o correto uso do conhecimento. (IRWIN, 1995, p. 75.)

Assim, a afirmação socrática da impossibilidade da akrasia significa que todas as decisões humanas são motivadas racionalmente, pois nossas escolhas que nos levam a agir são sempre levadas a cabo pela instância racional. De acordo com essa tese, quando erramos, nosso erro é involuntário, pois sempre agimos de acordo com o axioma eudaimonista, segundo o qual todos nós desejamos ser felizes. Portanto, o fato de errarmos se deve a termos tomado decisões baseados em opiniões que consideramos como verdadeiras, sendo elas, na verdade, falsas, o que nos leva a nos afastar da felicidade que mediatamente almejamos como fim último de todas as nossas ações.

Platão e Aristóteles rompem com esse modelo absolutamente racional da alma, concebendo outras fontes para as motivações que não a racional, admitindo, consequentemente, elementos não-cognitivos para as virtudes. Aristóteles, como notamos acima, retira por completo da virtude o aspecto cognitivo. Para o estagirita, a prudência (phronesis) deve ser buscada através de uma reflexão sobre aquelas pessoas que chamamos prudentes: um homem prudente é aquele "capaz de deliberar bem sobre o que é bom e vantajoso para ele próprio [...] como um meio para a boa vida em geral" (Aristóteles, 1994, 1140 a 20 ss.). Isso distinguirá a prudência de qualquer empreendimento teórico, pois:

[...] ninguém delibera sobre coisas que não podem variar [...] Logo, visto que o conhecimento científico envolve demonstração, enquanto coisas cujos principios fundamentais são variáveis não são passíveis de demonstração, porque tudo sobre elas é variável; e visto que ninguém delibera sobre coisas necessárias, segue-se que a prudência não é o mesmo que ciência [...] Não é ciência, porque questões de conduta admitem variação. (1140 b) 
Além disso, prossegue Aristóteles, dor e prazer não destroem crenças científicas (nenhuma tortura pode nos fazer descrer que um triângulo seja uma figura de três lados), porém um homem corrompido pela paixão e por vícios não consegue discernir mais os princípios que deve seguir para ser feliz; logo, fatores irracionais podem sim guiar as decisões humanas. Mais ainda: um conhecimento científico pode ser esquecido, porém um ato imprudente é motivado não por esquecimento dos princípios da ação, mas pela corrupção da vontade por vícios ou paixão. Além disso tudo:

[...] a prudência não é conhecimento de princípios gerais apenas [...] Ela deve também considerar os fatos particulares, já que se ocupa da ação, e a ação trata de coisas particulares. É por isso que homens que ignoram os princípios gerais são algumas vezes mais bem sucedidos na ação que outros que os conhecem [...] Embora os jovens possam ser peritos em geometria e matemática e ramos similares do conhecimento, não consideramos que um jovem possa ter prudência. A razão é que a prudência inclui um conhecimento de fatos particulares, e este é derivado da experiência que um jovem não possui, pois a experiência é fruto dos anos. (1141 b)

Como podemos ver, todas essas críticas de Aristóteles atacam uma concepção moral que não leva em consideração elementos não-cognitivos tanto da virtude quanto das motivações. Sócrates nega ambos: para ele, nossas escolhas são sempre motivadas racionalmente e a virtude se relaciona com um conhecimento estável (a technê moral) que, quando atingido, exclui necessariamente tudo o que é instável.

Assim, as críticas aristotélicas que mencionamos acima pressupõem justamente aquilo que Sócrates rechaça, ou seja, a importância de fatores não-cognitivos no que diz respeito à deliberação entre uma ação e outra e à virtude. Em suma: os fatores cruciais que distinguem o pensamento moral socrático daquele de Aristóteles são (1) a concepção socrática de alma, segundo a qual esta é tão somente racional (diferentemente de Aristóteles e também de Platão, que concebem funções ou partes distintas na alma que, como fontes de motivações, concorrem com a função ou parte racional na escolha da ação); e (2) a concepção socrática de virtude, segundo a qual a virtude é simultaneamente technê, phronesis e epistemê, as quais, uma vez atingidas, garantem a eudaimonia, pois tornam a alma absolutamente justa. Tal concepção de virtude se filia a um realismo de direito que concebe uma essência para a virtude e para o bem, e é justamente essa possibilidade que é atacada por Aristóteles: para o estagirita, o bem não é um gênero, não há essência do bem e, logo, não pode haver um conhecimento teórico único do bem em si mesmo.

Apresentamos aqui as críticas de Aristóteles quanto à concepção socrática de virtude para tornar clara, por contraste, a posição socrática, que é aquela de um extremo intelectualismo eudaimonista, segundo o qual nossa felicidade estará necessariamente assegurada quando possuirmos a technê do bem e do mal, o conhecimento da forma da virtude e do bem. Em outras palavras: o conhecimento de valores morais absolutos e universais.

A technê moral socrática será necessariamente universal, pois, sendo o conhecimento da forma única da virtude e do bem, não poderá ter uma concorrente, visto que não é possível que haja outra forma da virtude e do bem e, logo, uma outra technê da virtude e do bem. Sócrates busca, então, por esses valores morais universais: seu objetivo último será superar os valores morais fundados em falsas opiniões (e tal superação consiste na 'sabedoria humana' que 'se move como as estátuas de Dédalo', ou seja, que se desenvolve continuamente), buscando a obtenção de um conhecimento estável da virtude e do bem, a 'sabedoria divina', conhecimento possuído somente pelos deuses e que thes garante a felicidade.

Sócrates, porém, compreende que esse objetivo último e mediato que é a obtenção da sabedoria divina não é humanamente exequível. É um ideal que serve de guia para o homem, na medida em que 0 adverte continuamente de que não é supremamente sábio nem dono da verdade, o que o leva a questionar seus próprios princípios morais, bem como aqueles com os quais convive.

A ideia de uma sabedoria divina que se constitui racionalmente a partir da definição do bem e 
da virtude estabelece, no seio do pensamento socrático, um realismo de valores oposto ao relativismo sofístico. Para Sócrates, tanto a sabedoria humana quanto a divina partilham entre si o critério da racionalidade. Se a sabedoria divina é estável e atinge a verdade, a sabedoria humana, embora instável e incapaz de atingir a verdade de modo absoluto, é capaz de descartar falsidades, na medida em que avalia os valores morais quanto à sua consistência. Assim, tal humana sabedoria 'move' as afirmações dos homens quanto à moral, considerando-as racionalmente. Eis a sabedoria de Dédalo, a humana sabedoria de Sócrates, que, como ele mesmo diz na Apologia (1995, 23 ss), é de pouco ou nenhum valor se comparada à sabedoria divina, mas é aquela com a qual os homens se tornam sábios na medida do humanamente possível e sem a qual a vida não vale a pena ser vivida (38 a).

\section{REFERÊNCIAS BIBLIOGRÁFICAS:}

ARISTÓTELES. Ética Nicomaquéia. (trad. H. Rackham). 12 ed. Londres: Harvard University Press, 1994.

IRWIN, Terence. "Coercion and Objectivity in Plato's Dialectic" in Revue Internationale de Philosophie, 1986.

. Plato's Ethics. New York: Garland, 1995.

PLATÃO. Apologia. (trad. Harold North Fowler). 18 ed. Londres: Harvard University Press, 1995

(trad. Harold North Fowler). 18 ed. Londres: Harvard University Press, 1995.

Minos. (trad. W. R. M. Lamb). 7 ed. Londres: Harvard University Press, 1990.

. Eutífron. Trad. Harold North Fowler. 18 ed. Londres: Harvard University Press, 1995.

Recebido em fevereiro de 2012. Aprovado em maio de 2012. 